\title{
Effect of vitamin $E$ intake from food and supplement sources on plasma $\alpha$ - and $\gamma$-tocopherol concentrations in a healthy Irish adult population
}

\author{
Yang Zhao, Frank J. Monahan, Breige A. McNulty, Mike J. Gibney and Eileen R. Gibney* \\ UCD Institute of Food and Health, University College Dublin, Dublin 4, Republic of Ireland \\ (Submitted 14 March 2014 - Final revision received 1 July 2014 - Accepted 15 July 2014 - First published online 23 September 2014)
}

\section{Abstract}

Vitamin $\mathrm{E}$ is believed to play a preventive role in diseases associated with oxidative stress. The aims of the present study were to quantify vitamin $\mathrm{E}$ intake levels and plasma concentrations and to assess dietary vitamin E adequacy in Irish adults. Intake data from the National Adult Nutrition Survey were used; plasma samples were obtained from a representative cohort of survey participants. Plasma $\alpha$ - and $\gamma$-tocopherol concentrations were measured by HPLC. The main sources of vitamin $\mathrm{E}$ in the diet were 'butter, spreadable fats and oils' and 'vegetables and vegetable dishes'. When vitamin E intake from supplements was taken into account, supplements were found to be the main contributor, making a contribution of $29 \cdot 2 \%$ to vitamin E intake in the total population. Supplement consumers had significantly higher plasma $\alpha$-tocopherol concentrations and lower plasma $\gamma$-tocopherol concentrations when compared with non-consumers. Consumers of 'vitamin E' supplements had significantly higher vitamin E intake levels and plasma $\alpha$-tocopherol concentrations compared with consumers of other types of supplements, such as multivitamin and fish oil. Comparison with the Institute of Medicine Estimated Average Requirement of $12 \mathrm{mg} / \mathrm{d}$ indicated that when vitamin $\mathrm{E}$ intake from food and supplement sources was taken into account, $100 \%$ of the study participants achieved the recommended intake levels. When vitamin $\mathrm{E}$ intake from food sources was taken into account, only $68.4 \%$ of the females were found to achieve the recommended intake levels compared with $99 \cdot 2 \%$ of the males. The results of the present study show that dietary vitamin $\mathrm{E}$ intake has a significant effect on plasma $\alpha$ - and $\gamma$-tocopherol concentrations. Furthermore, they show that the consumption of supplements is a major contributor to overall intake and has a significant effect on plasma vitamin $\mathrm{E}$ concentrations in the Irish population.

\section{Key words: Vitamin E: Supplement types: Plasma tocopherol concentrations: Dietary intake}

Vitamin $\mathrm{E}$ is an important lipid-soluble antioxidant in vivo and is essential for the normal functioning of the musculoskeletal, reproductive, neural and vascular systems ${ }^{(1)}$. Vitamin $\mathrm{E}$ in the membrane of cells protects membranal phospholipid PUFA from oxidation, mediated by lipid radicals produced in the lipid peroxidation chain reaction ${ }^{(2)}$. Vitamin $\mathrm{E}$ is believed to play a preventive role in diseases associated with oxidative stress such as cancer, CVD, cataract formation, age-related macular degeneration and diabetes mellitus ${ }^{(3-6)}$.

Vitamin E exists as eight different isomers, four tocopherols $(\alpha-, \quad \beta-, \quad \gamma-$ and $\delta$-tocopherols) and four corresponding unsaturated tocotrienols ${ }^{(7)}$. $\alpha$-Tocopherol is reported to have the highest biological activity, with the body preferentially absorbing and using this form ${ }^{(8)}$. In contrast to $\alpha$-tocopherol, $\boldsymbol{\gamma}$-tocopherol is a powerful nucleophile that traps electrophilic mutagens in lipophilic compartments, which may protect lipids, DNA and proteins from peroxynitrite-dependent damage $^{(8)}$. The predominant form of vitamin $\mathrm{E}$ in food sources is $\gamma$-tocopherol, which is found in vegetable oils, grains, nuts and seeds ${ }^{(9)}$. A survey carried out in the USA estimated that approximately $70 \%$ of the vitamin $\mathrm{E}$ intake from food sources occurs in the form of $\gamma$-tocopherol ${ }^{(10)}$. The common form of vitamin $\mathrm{E}$ used in supplements is the acetate or succinate ester of $\alpha$-tocopherol ${ }^{(11)}$.

Studies have found that supplementation is generally related to increased dietary intake and plasma status of nutrients $^{(12,13)}$. In the Danish National Survey of Dietary Habits and Physical Activity (2000-4), supplement consumers were found to have a significantly higher intake of most micronutrients compared with non-consumers ${ }^{(12)}$, and in the Canadian Health Measures Survey, the consumption of vitamin D supplements was found to contribute to a higher plasma status of 25-hydroxyvitamin $\mathrm{D}^{(13)}$. Some surveys have also reported a positive correlation between vitamin $\mathrm{E}$ intake and plasma concentrations of tocopherols ${ }^{(14,15)}$. A French observational study showed that dietary vitamin $\mathrm{E}$ intake had a significant influence on plasma $\alpha$-tocopherol concentrations $^{(16)}$. In the US Women's Health Initiative 1994-6,

Abbreviations: EAR, estimated average requirements; EU, European Union; IOM, Institute of Medicine; supplements, vitamin E-containing supplements.

*Corresponding author: Dr E. R. Gibney, email eileen.gibney@ucd.ie 
it has been reported that vitamin $\mathrm{E}$ intake from supplements has a greater influence on plasma $\alpha$ - and $\gamma$-tocopherol concentrations than that from dietary sources ${ }^{(9)}$. In addition, supplemental vitamin $\mathrm{E}$ intake was found to be the strongest predictor of high plasma $\alpha$-tocopherol concentrations and low plasma $\gamma$-tocopherol concentrations in the US study $^{(9)} \cdot \alpha$-Tocopherol supplements may reduce circulating $\gamma$-tocopherol concentrations due to competition for hepatic transfer ${ }^{(17)}$. In many surveys, vitamin E-containing supplements (hereafter referred to as supplements) were included in the estimation of daily dietary intake and their relative contributions to intake were not considered. Moreover, the effect of specific types of supplements on vitamin $\mathrm{E}$ intake levels and plasma $\alpha$ - and $\gamma$-tocopherol concentrations remains relatively unknown. Although some information is available on nutrient intake from food and supplement sources in the Irish adult population ${ }^{(18,19)}$, neither plasma $\alpha$ - and $\gamma$-tocopherol concentrations nor the association between vitamin $\mathrm{E}$ intake and plasma $\alpha$ - and $\gamma$-tocopherol concentrations has been studied.

The aims of the present study were to determine mean daily vitamin $\mathrm{E}$ intake levels, assess dietary vitamin $\mathrm{E}$ intake adequacy compared with the recommended intake levels, and investigate the effect of vitamin $\mathrm{E}$ intake from food and supplement sources on plasma $\alpha$ - and $\gamma$-tocopherol concentrations in the Irish adult population.

\section{Experimental design}

\section{Study population}

Data for the present analysis were derived from the National Adult Nutrition Survey (NANS), a cross-sectional dietary survey carried out in 1500 healthy adults (740 males and 760 females) aged $\geq 18$ years from across the Republic of Ireland during the years 2008-2010 ${ }^{(20)}$. Ethical approval for the survey was obtained from the Human Ethics Research Committee of University College Dublin and the University College Cork Clinical Research Ethics Committee of the Cork Teaching Hospitals. Individuals who agreed to participate in the survey signed a written consent form in accordance with the Declaration of Helsinki. The participants were representative of the Irish adult population in terms of age, sex, social class and urban/rural distribution. More detailed descriptions of the sampling procedures and the survey methodology have been published elsewhere ${ }^{(20)}$. Of the 1500 participants, 1129 provided a blood sample, and data obtained from these subjects form the basis for the present study.

\section{Collection of dietary intake data}

Food and beverage intake data were collected using a $4 \mathrm{~d}$ semi-weighed food record, as described elsewhere ${ }^{(20)}$. The participants recorded detailed information on the amount and type of all foods, beverages and nutritional supplements consumed over four consecutive days and, where applicable, recorded details regarding recipes, cooking methods and leftovers. The participants recorded their food intake at the brand level where possible and kept aside the packaging of foods that they consumed, which was later used to update the Irish National Food and Ingredient Database version 3.0 $0^{(21)}$. A quantification protocol established by the Irish Universities Nutrition Alliance for the North/South Ireland Food Consumption Survey in 1997-9 was updated for the NANS and used during data entry ${ }^{(22)}$. Food intake was evaluated using Weighed Intake Software Package (WISP) version 3.0 (Tinuviel Software), which used data from McCance and Widdowson's 'The Composition of Food' fifth and sixth editions, plus all the nine supplemental volumes ${ }^{(23-33)}$. Each food and beverage was allocated an individual food code and subsequently assigned to one of the thirteen food groups for ease of analysis ${ }^{(20)}$. Modifications were made to the food composition database to include recipes of composite dishes, nutritional supplements, generic Irish foods that are commonly consumed and new foods on the market ${ }^{(34)}$.

\section{Estimation of vitamin E intake}

WISP provides information on the $\alpha$-tocopherol equivalents (total vitamin $\mathrm{E}$ intake) from foods, but does not distinguish between the natural form of vitamin $\mathrm{E}$ and the synthetic forms used in supplements. Therefore, to estimate vitamin $\mathrm{E}$ intake from both food sources and supplement sources, supplements were first identified based on the presence of the vitamin in the ingredient list using the Irish National Food and Ingredient Database version 3.0 or were checked directly in the retail outlet or on the manufacturers' website. Second, existing foods in the database were updated to reflect the current levels of $\alpha$-tocopherol equivalents by comparing with the US Department of Agriculture-National Nutrient Database for Standard Reference ${ }^{(35)}$. Overall, three nutrient descriptors were created for vitamin $\mathrm{E}$ intake, and these will be referred to throughout the article as follows: (1) all sources - vitamin E naturally occurring in foods and vitamin E from supplements; (2) food sources - vitamin E naturally occurring in only foods; (3) supplement sources - vitamin E from supplements. Vitamin E intake from all sources, food sources and supplement sources was adjusted for energy intake $(\mathrm{mg} / 10 \mathrm{MJ})$ in the total population. Among the nineteen food groups, seven individually contributed less than $3.7 \%$ to vitamin $\mathrm{E}$ intake and so were combined into one food group termed 'Others'. In total, thirteen food groups were taken into consideration as all sources of vitamin $\mathrm{E}$ intake.

A common qualitative classification of supplements was developed. The categories were 'multivitamin', 'fish oil', 'seed oil', 'fish and seed oil', and 'vitamin E'. A category termed 'Others' comprised non-specified vitamin E-containing supplements, including protein powders, protein and energy drinks, weight-loss products, isoflavone supplements, Se supplements and $\mathrm{Mg}$ supplements. Supplement consumers who consumed more than one type of supplement (multi-supplement consumers) were categorised using two approaches. First, as the number of supplement consumers of both multivitamin supplements and fish oil ( $n$ 22) was greater than that of consumers of other supplement combinations, they were assigned to the category 'multivitamin 
and fish oil'. Second, the remaining multi-supplement consumers ( $n$ 21) were assigned to the category of supplementation with the greatest contribution to vitamin $\mathrm{E}$ intake from supplement sources. Therefore, each supplement consumer belonged to only one category: 'multivitamin', 'fish oil', 'seed oil', 'fish and seed oil', 'vitamin E' or 'Others'.

\section{Blood sampling and biochemical analysis}

The blood collection protocol used in the NANS has been described elsewhere ${ }^{(36)}$. Blood processing and sample fractionations were performed at biological laboratories in University College Dublin and University College Cork, and samples were stored at $-80^{\circ} \mathrm{C}$ until analysis. All plasma samples for vitamin $\mathrm{E}$ analysis were collected in an EDTA-containing tube. Plasma vitamin E ( $\alpha$ - and $\gamma$-tocopherol) concentrations were determined by reversed-phase HPLC according to the method of Siluk et al. with slight modifications ${ }^{(37)}$. Aliquots $(200 \mu \mathrm{l})$ of plasma were vortex-mixed with $200 \mu \mathrm{l}$ of distilled water, $400 \mu \mathrm{l}$ of ethanol (containing $0.04 \%$ butylated hydroxytoluene) and $20 \mu \mathrm{l}$ of internal standard $(15 \mu \mathrm{g} / \mathrm{ml}, \alpha$-tocopherol acetate in ethanol). Extraction of $\alpha$ - and $\gamma$-tocopherols was performed with $800 \mu$ l hexane by vortex-mixing for 3 min and centrifuging at $3600 \mathrm{~g}$ for $10 \mathrm{~min}$ at $10^{\circ} \mathrm{C}$. The hexane extract was collected, and the solvent was evaporated using Speed Vac (Genevac). The residue was dissolved in $200 \mu \mathrm{l}$ of methanol, vortex-mixed for $30 \mathrm{~s}$ and transferred into an amber vial. The methanol extract $(20 \mu \mathrm{l})$ was analysed on an Agilent 1200 series HPLC system (Agilent Technologies, Inc.). Separation was achieved on a Zorbax Eclipse XDB-C18 column $(150 \mathrm{~mm} \times 4 \mathrm{~mm}$ inner diameter; $5 \mu \mathrm{m}$ particle size $)$ with a RX-C8 guard column $(12.5 \mathrm{~mm} \times 4.6 \mathrm{~mm}$ inner diameter; $5 \mu \mathrm{m}$ particle size). The column was attached to a 1200 series diode array detector (Agilent Technologies, Inc.), set at an excitation wavelength of $295 \mathrm{~nm}$ for $\alpha$ - and $\gamma$-tocopherols and of $298 \mathrm{~nm}$ for $\alpha$-tocopherol acetate ${ }^{(37)}$. The mobile phase was $100 \%$ methanol at a flow rate $1 \mathrm{ml} / \mathrm{min}$.

A UV spectrophotometer (UV mini-1240; Shimadzu) was used to determine the concentrations of standard solutions of $\alpha$-tocopherol, $\gamma$-tocopherol and $\alpha$-tocopherol acetate according to published molar extinction coefficients ${ }^{(38)}$. Plasma $\alpha$ - and $\gamma$-tocopherol concentrations were calculated by comparing with a corresponding calibration curve. The recovery of the internal standard was $98 \%$ for $\alpha$-tocopherol and $101 \%$ for $\gamma$-tocopherol. This is similar to original findings from the method of Siluk et al. ${ }^{(37)}$, where the accuracy of recovery ranged from 96 to $106 \%$ for $\alpha$-tocopherol and from 101 to $109 \%$ for $\gamma$-tocopherol.

\section{Statistical analyses}

All statistical analyses were carried out using SPSS version 20.0 (SPSS, Inc.). Compliance to the current $\mathrm{RDA}^{(39)}$ and estimated average requirements $(\mathrm{EAR})^{(40)}$ was estimated using the method of Wearne \& Day ${ }^{(41)}$. Of the 1129 participants, 420 who were considered to have under-reported energy intake using the Goldberg method ${ }^{(42)}$ were excluded from the compliance analysis, leaving 709 participants. All the
1129 participants were included in all other analyses. Vitamin E intake from all sources, food sources and supplement sources was calculated, and the relative contributions of the thirteen food groups to vitamin $\mathrm{E}$ intake in the total population were evaluated. Energy-adjusted vitamin $\mathrm{E}$ intake (mg/10 MJ) from all sources, food sources and supplement sources was calculated for the total population, and differences across age groups (18-35, 36-50, 50-64 and >64 years) and sexes were determined using a two-way ANOVA, followed by Tukey's post hoc test. Data on the intake levels and plasma concentrations of vitamin E were skewed and therefore log-transformed before statistical analyses. Data on plasma $\alpha$ - and $\gamma$-tocopherol concentrations of the total population and supplement consumers and non-consumers within each age group and sex were analysed using two-way ANOVA. The participants were also divided into quartiles of vitamin $\mathrm{E}$ intake from all sources, food sources and supplement sources, and a general linear model univariate analysis (adjusted for age and sex) was used to assess differences in plasma $\alpha$ - and $\gamma$-tocopherol concentrations across quartiles of intake.

\section{Results}

\section{Study population characteristics}

A total of 1129 Irish adults were included in the present study. The participants were representative of the Irish adult population in terms of age, sex, social class and location ${ }^{(18,20)}$. In total, $70 \%$ of the males and $56 \%$ of the females were classified as overweight/obese, and $20 \%$ of the participants were current smokers. Furthermore, $31 \%$ of the participants consumed at least one nutritional supplement, with more females (36\%) consuming nutritional supplements than males (26\%) (online supplementary Table S1).

\section{Vitamin E intake in the total population}

The mean daily vitamin $\mathrm{E}$ intake from all sources, food sources and supplement sources was $13.8,9.8$ and $21.9 \mathrm{mg} / \mathrm{d}$, respectively, in the total population (online supplementary Table S2). There was a stepwise increase in vitamin $\mathrm{E}$ intake from all sources across age groups, with the lowest intake being found in the 18-35 years age group. Vitamin E intake from all sources was slightly higher in females than in males $(14.5$ v. $13.2 \mathrm{mg} / \mathrm{d}$ ). However, this seemed to be due to supplement intake, as female supplement consumers had a higher intake than male supplement consumers $(28.6 v .14 \cdot 4 \mathrm{mg} / \mathrm{d})$. Vitamin $\mathrm{E}$ intake from food sources was higher in males than in females $(10.7 v .8 .9 \mathrm{mg} / \mathrm{d})$.

The percentage of Irish adults meeting dietary vitamin $\mathrm{E}$ intake requirements, including the European Union (EU) RDA $(12 \mathrm{mg} / \mathrm{d})^{(39)}$ and the Institute of Medicine (IOM) $\mathrm{EAR}^{(40)}$, was determined (Table 1). On using the IOM EAR or EU RDA of $12 \mathrm{mg} / \mathrm{d}, 100 \%$ of the study population was found to achieve the recommended intake levels; however, when intake from food sources was considered, only $99 \%$ of the males and $68 \%$ of the females were found to achieve the recommended intake levels. This disparity between 
Table 1. Percentage of Irish adults meeting dietary vitamin $E$ intake requirements including the Institute of Medicine estimated average requirement $(12 \mathrm{mg} / \mathrm{d})$

\begin{tabular}{lccc}
\hline & Total population & Males & Females \\
\hline All sources* & $100 \cdot 0$ & $100 \cdot 0$ & $100 \cdot 0$ \\
Food sources & 86.9 & 99.2 & 68.4 \\
\hline
\end{tabular}

* Includes intake from both food and supplement sources.

males and females is probably due to the absence of sexspecific recommendations, with an intake of $12 \mathrm{mg} / \mathrm{d}$ being recommended for both males and females; as such males, with considerably higher energy and fat intakes than females, more readily achieve this recommended intake level ${ }^{(20)}$. Less than $1 \%$ of the participants were found to have intake levels above the tolerable upper intake level of $300 \mathrm{mg} / \mathrm{d}^{(43)}$ (data not shown).

The percentage of contribution of the thirteen food groups to the mean daily vitamin $\mathrm{E}$ intake in the total population was assessed (Fig. 1). When vitamin $\mathrm{E}$ intake from food sources was taken into account, the food group butter, spreadable fats and oils' was found to be the main source of dietary vitamin $\mathrm{E}$ intake, followed by 'vegetables and vegetable dishes'. When vitamin $\mathrm{E}$ intake from supplements was taken into account, supplements were found to make a significant contribution, accounting for $29 \%$ of dietary vitamin $\mathrm{E}$ intake in the total population. Of the $31 \%$ of participants taking nutritional supplements, $18 \%$ (17\% of the males and
$20 \%$ of the females) consumed at least one supplement specifically containing vitamin E. When supplement consumers and non-consumers were analysed separately, ranking of the contribution of food groups to vitamin $\mathrm{E}$ intake remained the same, across both sets of participants. Thus, supplement consumers and non-consumers seemed to have similar dietary patterns with respect to vitamin $\mathrm{E}$ intake.

The energy-adjusted mean daily vitamin E intake (mg/10 MJ per d) from all sources, food sources and supplement sources is summarised in Table 2. A stepwise increase in vitamin $\mathrm{E}$ intake from all sources and food sources was observed in the total population with an increase in age $(P<0 \cdot 001)$. A significant effect of sex was found across quartiles of intake from all sources, food sources and supplement sources, with a higher vitamin $\mathrm{E}$ intake being found in females than in males $(P<0 \cdot 001)$. No age $\times$ sex interactions were observed across groups.

\section{Plasma vitamin E concentrations in the Irish population}

Plasma $\alpha$ - and $\gamma$-tocopherol concentrations of the total population, supplement consumers and non-consumers are given in Tables 3 and 4, respectively. Supplement consumers had significantly higher plasma $\alpha$-tocopherol concentrations $(P<0.001)$ and lower plasma $\gamma$-tocopherol concentrations $(P<0 \cdot 001)$ when compared with non-consumers across all age groups. The mean plasma $\alpha$ - and $\gamma$-tocopherol concentrations of supplement consumers, across all age groups, were 28.1 and $1.5 \mu \mathrm{mol} / \mathrm{l}$, while those of non-consumers

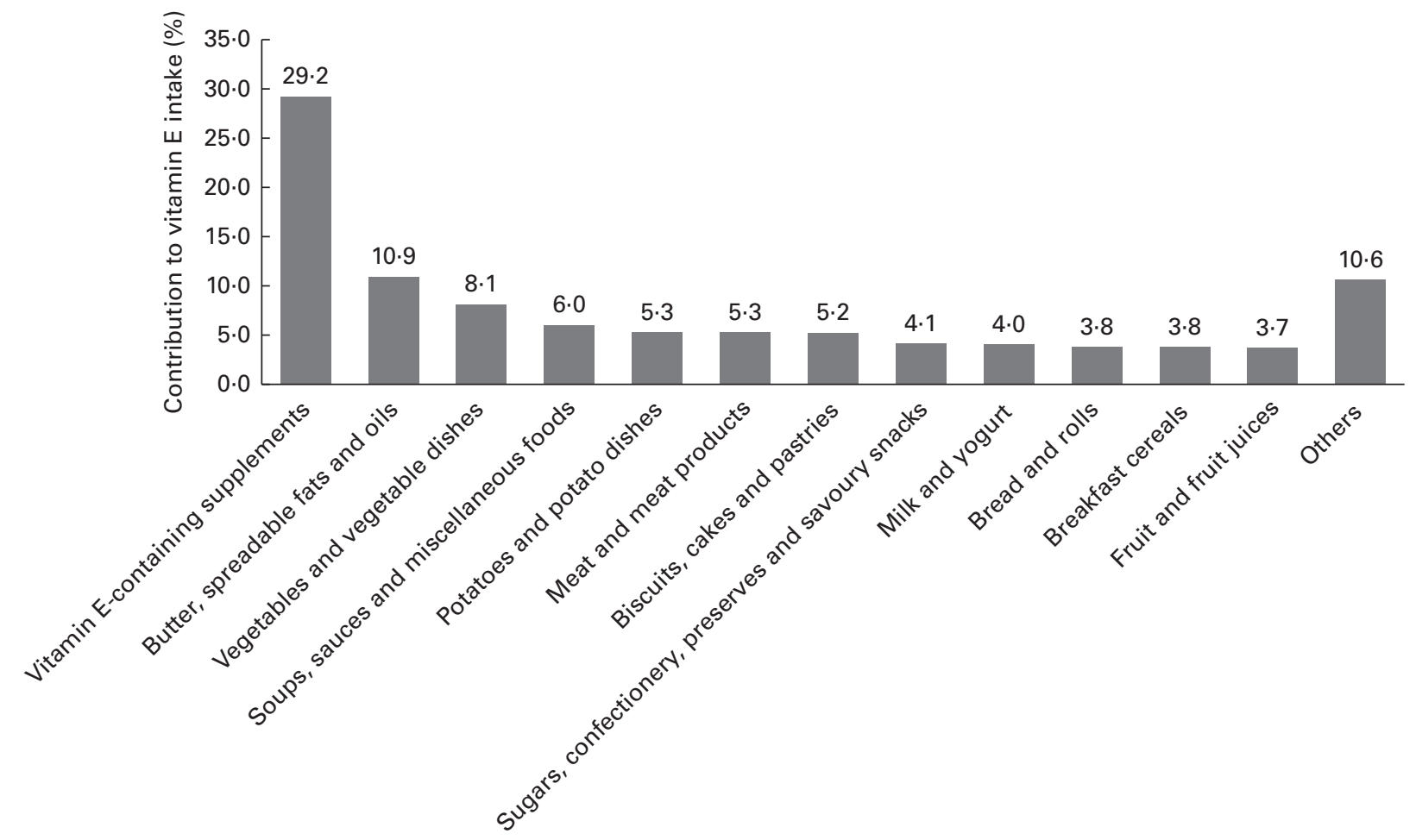

Fig. 1. Percentage of contribution (\%) of the thirteen food groups to mean daily intake of vitamin $\mathrm{E}$ in the total population. Others include 'grains, rice, pasta and savoury snacks', 'fish and fish dishes', 'eggs and egg dishes', 'nuts, seeds, herbs and spices', 'creams, ice creams and chilled desserts', 'cheeses' and 'beverages'. 
Table 2. Effect of age and sex on the energy-adjusted mean daily vitamin $E$ intake (mg/10 MJ per d) from all sources, food sources and supplement sources

(Number of participants, mean values and standard deviations)

\begin{tabular}{|c|c|c|c|c|c|c|c|c|c|c|c|c|c|c|c|}
\hline & \multicolumn{12}{|c|}{ Age groups (years) } & & & \\
\hline & \multicolumn{3}{|c|}{$18-35$} & \multicolumn{3}{|c|}{$36-50$} & \multicolumn{3}{|c|}{$51-64$} & \multicolumn{3}{|c|}{$>64$} & \multicolumn{3}{|c|}{$P$ (two-way ANOVA) $\dagger$} \\
\hline & $n$ & Mean & SD & $n$ & Mean & SD & $n$ & Mean & SD & $n$ & Mean & SD & Age & Sex & $\begin{array}{c}\text { Age } \times \\
\text { sex }\end{array}$ \\
\hline \multicolumn{16}{|l|}{ All sources } \\
\hline All & 428 & $13 \cdot 6^{b}$ & 24.9 & 332 & $15 \cdot 1^{\mathrm{b}}$ & $28 \cdot 0$ & 224 & $20 \cdot 0^{a}$ & 37.4 & 145 & $22 \cdot 2^{\mathrm{a}}$ & 54.0 & $<0.001$ & $<0.001$ & 0.094 \\
\hline Males & 232 & $13 \cdot 6$ & $32 \cdot 1$ & 154 & $11.5^{\star}$ & $6 \cdot 4$ & 114 & $13 \cdot 4^{\star}$ & $9 \cdot 0$ & 66 & $13 \cdot 5^{*}$ & $6 \cdot 8$ & & & \\
\hline Females & 196 & $13 \cdot 6$ & 11.8 & 178 & $18 \cdot 3$ & $37 \cdot 6$ & 110 & $26 \cdot 7$ & $51 \cdot 8$ & 79 & 29.6 & $72 \cdot 3$ & & & \\
\hline \multicolumn{16}{|c|}{ Food sources } \\
\hline All & 428 & $10 \cdot 4^{c}$ & $4 \cdot 2$ & 332 & $11 \cdot 4^{\mathrm{b}, \mathrm{c}}$ & 4.4 & 224 & $12 \cdot 6^{a, b}$ & $5 \cdot 6$ & 145 & $13 \cdot 2^{\mathrm{a}}$ & $6 \cdot 3$ & $<0.001$ & $<0.001$ & 0.884 \\
\hline Males & 232 & $9 \cdot 7^{*}$ & 3.9 & 154 & $10 \cdot 6^{*}$ & 4.4 & 114 & $11 \cdot 5^{\star}$ & 5.5 & 66 & $12 \cdot 4$ & $5 \cdot 8$ & & & \\
\hline Females & 196 & $11 \cdot 2$ & $4 \cdot 3$ & 178 & $12 \cdot 0$ & $4 \cdot 2$ & 110 & $13 \cdot 6$ & 5.5 & 79 & $13 \cdot 8$ & $6 \cdot 6$ & & & \\
\hline \multicolumn{16}{|c|}{ Supplement sources (only consumers) } \\
\hline All & 65 & $21 \cdot 2$ & 59.5 & 49 & $25 \cdot 6$ & 67.4 & 59 & $28 \cdot 1$ & 67.9 & 35 & $37 \cdot 6$ & $103 \cdot 4$ & 0.841 & $<0.001$ & 0.119 \\
\hline Males & 36 & $25 \cdot 2$ & $77 \cdot 2$ & 22 & $6 \cdot 7^{*}$ & 9.9 & 25 & $8 \cdot 7$ & $11 \cdot 2$ & 15 & $4 \cdot 7^{\star}$ & 4.5 & & & \\
\hline Females & 29 & $16 \cdot 4$ & $24 \cdot 2$ & 27 & $41 \cdot 0$ & $88 \cdot 0$ & 34 & $42 \cdot 4$ & 86.7 & 20 & $62 \cdot 3$ & $132 \cdot 8$ & & & \\
\hline
\end{tabular}

${ }^{a, b, c}$ Mean values with unlike superscript letters were significantly different between the age groups $(P<0.05)$.

${ }^{*}$ Mean values were significantly different between sexes within each age group $(P<0.05)$.

†Differences across age groups and sexes were assessed using two-way ANOVA followed by Tukey's post hoc test.

were 25.1 and $1.8 \mu \mathrm{mol} / \mathrm{l}$, respectively (data not shown). There were significant differences in plasma $\alpha$-tocopherol concentrations among the age groups $(P<0 \cdot 001)$ in the total population, non-consumers and supplement consumers, with the concentrations increasing with an increase in age (Table 3). An age $\times$ sex interaction was observed in the total population, with males in the 51-64 and $>64$ years age groups, but not in the $18-35$ and $36-50$ years age groups, having lower plasma $\alpha$-tocopherol concentrations compared with females in the same age groups $(P=0 \cdot 007$; Table 3$)$

When plasma $\gamma$-tocopherol concentrations were evaluated (Table 4), an effect of age was found in the total population $(P=0.004)$ and non-consumers of supplements $(P<0.001)$, whereby the 51-64 years age group had higher plasma $\gamma$-tocopherol concentrations than the other age groups. No sex effect or age $\times$ sex interactions were observed across groups.

\section{Effect of food and supplement sources on plasma vitamin E concentrations}

To further investigate the effect of vitamin $\mathrm{E}$ intake sources on plasma $\alpha$ - and $\gamma$-tocopherol concentrations, the total population was divided into quartiles of vitamin $\mathrm{E}$ intake from all sources (Table 5) and food sources (Table 6), while supplement consumers were divided into quartiles of vitamin E intake from supplement sources (Table 7). Plasma $\alpha$ - and $\boldsymbol{\gamma}$-tocopherol concentrations were significantly different across quartiles of vitamin $E$ intake from all sources

Table 3. Effect of age and sex on plasma $\alpha$-tocopherol concentrations ( $\mu \mathrm{mol} / /)$ in the total population, supplement consumers and non-consumers (Number of participants, mean values and standard deviations)

\begin{tabular}{|c|c|c|c|c|c|c|c|c|c|c|c|c|c|c|c|}
\hline \multirow{3}{*}{$\begin{array}{l}\alpha \text {-Tocopherol } \\
\text { concentrations }\end{array}$} & \multicolumn{12}{|c|}{ Age groups (years) } & & & \\
\hline & \multicolumn{3}{|c|}{$18-35$} & \multicolumn{3}{|c|}{$36-50$} & \multicolumn{3}{|c|}{$51-64$} & \multicolumn{3}{|c|}{$>64$} & \multicolumn{3}{|c|}{$P$ (two-way ANOVA) $\dagger$} \\
\hline & $n$ & Mean & $\overline{S D}$ & $n$ & Mean & SD & $n$ & Mean & $\overline{S D}$ & $n$ & Mean & $\overline{S D}$ & Age & Sex & Age $\times$ sex \\
\hline \multicolumn{16}{|l|}{ Total population } \\
\hline All & 428 & $22 \cdot 18^{\mathrm{b}}$ & $5 \cdot 30$ & 332 & $27 \cdot 22^{a}$ & $6 \cdot 81$ & 224 & $28 \cdot 62^{\mathrm{a}}$ & $7 \cdot 24$ & 145 & $27 \cdot 59^{\mathrm{a}}$ & $7 \cdot 78$ & $<0.001$ & 0.006 & 0.007 \\
\hline Males & 232 & $22 \cdot 19$ & 5.57 & 154 & 27.50 & $7 \cdot 29$ & 114 & $27 \cdot 75^{*}$ & $7 \cdot 82$ & 66 & $25 \cdot 72^{\star}$ & 7.22 & & & \\
\hline Females & 196 & $22 \cdot 16$ & 4.97 & 178 & 26.98 & $6 \cdot 38$ & 110 & 29.52 & 6.50 & 79 & $29 \cdot 15$ & 7.92 & & & \\
\hline \multicolumn{16}{|l|}{ Non-consumers } \\
\hline All & 363 & $21 \cdot 83^{\mathrm{c}}$ & $4 \cdot 81$ & 283 & $26 \cdot 73^{\mathrm{b}}$ & $6 \cdot 48$ & 165 & $28 \cdot 37^{a}$ & $7 \cdot 14$ & 110 & $26 \cdot 67^{b}$ & 7.43 & $<0.001$ & 0.283 & 0.096 \\
\hline Males & 196 & 22.02 & 4.99 & 132 & $27 \cdot 15$ & 7.40 & 89 & 28.01 & 8.24 & 51 & $25 \cdot 39$ & $6 \cdot 97$ & & & \\
\hline Females & 167 & 21.60 & 4.60 & 151 & $26 \cdot 36$ & 5.55 & 76 & $28 \cdot 78$ & $5 \cdot 62$ & 59 & $27 \cdot 77$ & 7.69 & & & \\
\hline \multicolumn{16}{|c|}{ Supplement consumers } \\
\hline All & 65 & $24 \cdot 12^{b}$ & $7 \cdot 21$ & 49 & $30.09^{a}$ & 7.97 & 59 & $29 \cdot 32^{a}$ & 7.52 & 35 & $30 \cdot 48^{a}$ & 8.24 & $<0.001$ & 0.001 & 0.355 \\
\hline Males & 36 & $23 \cdot 10$ & 8.07 & 22 & 29.60 & $6 \cdot 31$ & 25 & $26 \cdot 80^{*}$ & $6 \cdot 14$ & 15 & $26 \cdot 85^{\star}$ & $8 \cdot 18$ & & & \\
\hline Females & 29 & $25 \cdot 39$ & $5 \cdot 87$ & 27 & 30.49 & $9 \cdot 20$ & 34 & $31 \cdot 17$ & 7.97 & 20 & $33 \cdot 21$ & $7 \cdot 33$ & & & \\
\hline
\end{tabular}

a,b,c Mean values with unlike superscript letters were significantly different between the age groups $(P<0.05)$.

${ }^{\star}$ Mean values were significantly different between sexes within each age group $(P<0.05)$.

†Differences across age groups and sexes were assessed using two-way ANOVA followed by Tukey's post hoc test. 
Table 4. Effect of age and sex on plasma $\gamma$-tocopherol concentrations $(\mu \mathrm{mol} / \mathrm{l})$ in the total population, supplement consumers and non-consumers (Number of participants, mean values and standard deviations)

\begin{tabular}{|c|c|c|c|c|c|c|c|c|c|c|c|c|c|c|c|}
\hline \multirow{3}{*}{$\begin{array}{l}\gamma \text {-Tocopherol } \\
\text { concentrations }\end{array}$} & \multicolumn{12}{|c|}{ Age groups (years) } & & & \\
\hline & \multicolumn{3}{|c|}{$18-35$} & \multicolumn{3}{|c|}{$36-50$} & \multicolumn{3}{|c|}{$51-64$} & \multicolumn{3}{|c|}{$>64$} & \multicolumn{3}{|c|}{$P($ two-way ANOVA)* } \\
\hline & $N$ & Mean & SD & $n$ & Mean & SD & $n$ & Mean & SD & $n$ & Mean & SD & Age & Sex & Age $\times$ sex \\
\hline \multicolumn{16}{|l|}{ Total population } \\
\hline All & 428 & $1 \cdot 60^{\mathrm{b}}$ & 0.89 & 332 & $1 \cdot 78^{a, b}$ & 0.97 & 224 & $1.89^{\mathrm{a}}$ & 0.94 & 145 & $1 \cdot 70^{a, b}$ & 0.94 & 0.004 & 0.501 & 0.088 \\
\hline Males & 232 & 1.60 & 0.81 & 154 & $1 \cdot 10$ & 1.29 & 114 & 1.90 & 0.91 & 66 & 1.65 & 0.90 & & & \\
\hline Females & 196 & 1.59 & 0.80 & 178 & 1.67 & 0.84 & 110 & 1.87 & 0.97 & 79 & 1.75 & 0.98 & & & \\
\hline \multicolumn{16}{|l|}{ Non-consumers } \\
\hline All & 363 & $1 \cdot 61^{\mathrm{b}}$ & 0.77 & 283 & $1 \cdot 84^{a, b}$ & 0.96 & 165 & $2 \cdot 05^{\mathrm{a}}$ & 0.96 & 110 & $1 \cdot 79^{b}$ & 0.95 & $<0.001$ & 0.585 & 0.083 \\
\hline Males & 196 & 1.61 & 0.80 & 132 & 1.96 & 1.08 & 89 & 2.04 & 0.94 & 51 & 1.64 & 0.93 & & & \\
\hline Females & 167 & 1.61 & 1.01 & 151 & 1.73 & 0.84 & 76 & 2.06 & 0.98 & 59 & 1.92 & 0.96 & & & \\
\hline \multicolumn{16}{|c|}{ Supplement consumers } \\
\hline All & 65 & 1.53 & 0.95 & 49 & 1.47 & 0.96 & 59 & 1.44 & 0.71 & 35 & 1.44 & 0.87 & 0.214 & 0.058 & 0.539 \\
\hline Males & 36 & 1.56 & 1.00 & 22 & 1.63 & 1.17 & 25 & 1.42 & 0.59 & 15 & 1.71 & 0.84 & & & \\
\hline Females & 29 & 1.49 & 0.88 & 27 & 1.34 & 0.75 & 34 & 1.45 & 0.79 & 20 & 1.23 & 0.85 & & & \\
\hline
\end{tabular}

a,b Mean values with unlike superscript letters were significantly different between the age groups $(P<0.05)$.

*Differences across age groups and sexes were assessed using two-way ANOVA followed by Tukey's post hoc test.

$(P<0 \cdot 001$ and 0.005, respectively), with plasma $\alpha$-tocopherol concentrations increasing (by $9 \%$ ) and plasma $\gamma$-tocopherol concentrations decreasing (by 13\%) with an increase in intake. There was a significant effect of food sources on plasma $\alpha$-tocopherol concentrations $(P=0.027)$, which increased by $6 \%$, but there was no change in plasma $\boldsymbol{\gamma}$-tocopherol concentrations across quartiles of intake (Table 6). Similarly, in supplement consumers, a significant effect of vitamin $\mathrm{E}$ intake from supplement sources on plasma $\alpha$-tocopherol concentrations $(P=0 \cdot 001)$, but not on plasma $\gamma$-tocopherol concentrations, was observed across quartiles of intake. However, among supplement consumers, those in the highest quartile had significantly higher intake levels $(72 \mathrm{mg} / \mathrm{d})$ and higher plasma $\alpha$-tocopherol concentrations $(32 \mu \mathrm{mol} / \mathrm{l})$.

The range of manufacturers' recommended doses in the different types of supplements was large, with one 'vitamin E' supplement providing a high dose $(546 \mathrm{mg} / \mathrm{d})$, while the lowest recommended dose $(0.2 \mathrm{mg} / \mathrm{d})$ was observed in fish oil-type supplements (Table 8). The vast majority of supplement consumers consumed either fish oil or multivitamin supplements, with only $0 \cdot 4 \%$ of the total population taking a 'vitamin E' supplement. There was a significant difference in vitamin $\mathrm{E}$ intake from supplements across consumers of different types of supplements $(P<0 \cdot 001)$, with 'vitamin E' supplements providing a considerably higher amount of vitamin $\mathrm{E}$ than all other types of supplements. No significant difference was observed in vitamin $\mathrm{E}$ intake from food sources across consumers of different types of supplements, but there was a significant difference in plasma $\alpha$-tocopherol concentrations $(P<0 \cdot 001)$ across consumers of different types of supplements, with 'vitamin E' supplement consumers having significantly higher plasma $\alpha$-tocopherol concentrations than consumers of other types of supplements.

\section{Discussion}

In the present study, Irish adults were found to generally achieve the EU RDA and IOM EAR of $12 \mathrm{mg} / \mathrm{d}$. The raw vitamin $\mathrm{E}$ intake values reported herein $(13$ and $15 \mathrm{mg} / \mathrm{d}$ from all sources and 11 and $9 \mathrm{mg} / \mathrm{d}$ from food sources for males and females, respectively) are comparable to those reported in other international studies ${ }^{(44-47)}$. The Polish National Nutrient Intake Survey (2001) reported mean daily vitamin E intake values, including for supplement sources, of $16 \mathrm{mg} / \mathrm{d}$ for males and $11 \mathrm{mg} / \mathrm{d}$ for females ${ }^{(46)}$. The UK National Diet and Nutrition Survey (NDNS, 2004) published values of 13 and $15 \mathrm{mg} / \mathrm{d}$ for the mean daily vitamin $\mathrm{E}$ intake from all

Table 5. Plasma $\alpha$ - and $\gamma$-tocopherol concentrations ( $\mu \mathrm{mol} / \mathrm{l})$ across quartiles of daily vitamin $E$ intake from all sources (Mean values and standard deviations, $n$ 1129)

\begin{tabular}{|c|c|c|c|c|c|c|c|c|c|}
\hline & \multicolumn{8}{|c|}{ Quartiles } & \multirow[b]{3}{*}{$P(\mathrm{GLM})^{\star}$} \\
\hline & \multicolumn{2}{|c|}{1} & \multicolumn{2}{|c|}{2} & \multicolumn{2}{|c|}{3} & \multicolumn{2}{|c|}{4} & \\
\hline & Mean & SD & Mean & SD & Mean & SD & Mean & SD & \\
\hline Intake levels & $4.92^{\mathrm{c}}$ & 1.20 & $8 \cdot 08^{b, c}$ & 0.80 & $11 \cdot 39^{b}$ & 1.27 & $31.00^{\mathrm{a}}$ & $57 \cdot 39$ & $<0.001$ \\
\hline$\alpha$-Tocopherol concentrations & $24 \cdot 68^{\mathrm{b}}$ & 7.00 & $25 \cdot 29^{b}$ & 6.54 & $25.59^{a, b}$ & 6.45 & $26 \cdot 98^{a}$ & 8.00 & $<0.001$ \\
\hline$\gamma$-Tocopherol concentrations & $1 \cdot 81^{\mathrm{a}}$ & 0.91 & $1 \cdot 76^{\mathrm{a}}$ & 0.88 & $1 \cdot 75^{a, b}$ & 0.88 & $1.57^{\mathrm{b}}$ & 0.94 & 0.005 \\
\hline
\end{tabular}

GLM, general linear model.

${ }^{a, b, c}$ Mean values with unlike superscript letters were significantly different between the quartiles $(P<0.05)$.

${ }^{\star}$ GLM univariate analysis, adjusted for age and sex, was carried out to determine significance. 
Table 6. Plasma $\alpha$ - and $\gamma$-tocopherol concentrations ( $\mu \mathrm{mol} / \mathrm{l})$ across quartiles of daily vitamin $E$ intake from food sources (Mean values and standard deviations, $n$ 1129)

\begin{tabular}{|c|c|c|c|c|c|c|c|c|c|}
\hline & \multicolumn{8}{|c|}{ Quartiles } & \multirow[b]{3}{*}{$P(\mathrm{GLM})^{\star}$} \\
\hline & \multicolumn{2}{|c|}{1} & \multicolumn{2}{|c|}{2} & \multicolumn{2}{|c|}{3} & \multicolumn{2}{|c|}{4} & \\
\hline & Mean & SD & Mean & SD & Mean & SD & Mean & SD & \\
\hline Intake levels & $4 \cdot 66^{d}$ & $1 \cdot 10$ & $7 \cdot 62^{c}$ & 0.72 & $10 \cdot 38^{b}$ & 0.96 & $16 \cdot 55^{\mathrm{a}}$ & $4 \cdot 60$ & $<0.001$ \\
\hline$\alpha$-Tocopherol concentrations & $24 \cdot 79^{\mathrm{b}}$ & $7 \cdot 03$ & $25 \cdot 70^{a, b}$ & $6 \cdot 26$ & $25 \cdot 73^{a, b}$ & $7 \cdot 19$ & $26 \cdot 13^{a}$ & $7 \cdot 32$ & 0.027 \\
\hline$\gamma$-Tocopherol concentrations & $1 \cdot 77$ & 0.87 & $1 \cdot 78$ & 0.92 & $1 \cdot 64$ & 0.92 & $1 \cdot 70$ & 0.91 & 0.181 \\
\hline
\end{tabular}

sources and of 11 and $8 \mathrm{mg} / \mathrm{d}$ for that from food sources for males and females, respectively ${ }^{(47)}$, and the Survey of Lifestyle, Attitudes and Nutrition in Ireland (SLAN 2007) reported values of $8.8 \mathrm{mg} / \mathrm{d}$ and $9.1 \mathrm{mg} / \mathrm{d}$ for the mean dietary vitamin $\mathrm{E}$ intake from food sources for males and females, respectively ${ }^{(18)}$. The US National Health and Nutrition Examination Survey (NHANES) 2001-2 reported values of $7 \cdot 0$ and $6 \cdot 1 \mathrm{mg} / \mathrm{d}$ for the mean vitamin $\mathrm{E}$ intake from foods for males and females, respectively ${ }^{(45)}$

Comparison of the mean daily intake values of the study population with the IOM EAR or EU RDA showed that the prevalence of inadequate vitamin $\mathrm{E}$ intake from food sources was less than $1 \%$ in males and $32 \%$ in females; however, $100 \%$ of both males and females achieved the recommended intake levels when intake from food and supplement sources was taken into account, indicating that the consumption of supplements contributed to dietary adequacy in females. The reason for $99 \%$ of the Irish males achieving the recommended intake from food sources alone is that they had significantly higher energy and fat intakes compared with females, which contributed to a higher vitamin $\mathrm{E}$ intake ${ }^{(20)}$. Furthermore, in the present study, the consumption of supplements was found to contribute $29 \%$ to vitamin E intake in the total population; a previous Irish national consumption survey published 10 years ago (The North/ South Irish Food Consumption Survey) has reported that supplement use contributed only $6 \%$ to the mean daily vitamin $\mathrm{E}$ intake in males and $12 \%$ in females ${ }^{(19)}$. This suggests that the consumption of supplements by the Irish population has increased over the last 10 years. The UK survey (NDNS, 2004) also demonstrated the considerable contribution of supplement sources to vitamin $\mathrm{E}$ intake in the total population, increasing the mean daily intake over that from food sources by $26 \%$ for males and $85 \%$ for females ${ }^{(47)}$. In contrast to the present results, in the USA (NHANES 2003-6), 58\% of adults were found to have intake levels below the IOM EAR when intake from supplements was taken into account ${ }^{(48)}$.

The main sources of vitamin $\mathrm{E}$ in the Irish adult diet are 'butter, spreadable fats and oils' and 'vegetables and vegetable dishes'. 'Butter, spreadable fats and oils' are rich sources of vitamin $\mathrm{E}^{(9)}$ and also consumed very frequently in small portions by Irish adults, with an average of $4.4 \%$ energy being derived from fat in this cohort ${ }^{(20)}$. 'Vegetables and vegetable dishes' are consumed very frequently in large portions $(148 \mathrm{~g} / \mathrm{d})$ and vegetable dishes often contain added butter and sauce, which are rich sources of vitamin $\mathrm{E}^{(20)}$. In agreement with the present findings, the main contributor to dietary vitamin $\mathrm{E}$ intake in the UK survey (NDNS, 2004) was also 'fat spreads', making a contribution of $18 \%$ to dietary vitamin $\mathrm{E}$ intake ${ }^{(47)}$; however, the second contributor was 'cereals and cereal products', making a contribution of $17 \%$ to dietary vitamin $\mathrm{E}$ intake. It is important to note that 'breakfast cereals', which were categorised within 'cereals and cereals products' in the UK survey, contributed $5 \%$ to dietary intake in the total population. This is similar to the present study where the 'breakfast cereals' group contributed 3.8\% to Irish vitamin E intake from all sources. The US Continuing Survey of Food Intakes by Individuals (CSFII) carried out from 1994 to 1996 reported that the two main contributors to dietary vitamin $\mathrm{E}$

Table 7. Plasma $\alpha$ - and $\gamma$-tocopherol concentrations ( $\mu \mathrm{mol} / \mathrm{l})$ across quartiles of daily vitamin $\mathrm{E}$ intake from supplement sources (only consumers)

(Mean values and standard deviations, $n$ 208)

\begin{tabular}{|c|c|c|c|c|c|c|c|c|c|}
\hline & \multicolumn{8}{|c|}{ Quartiles } & \multirow[b]{3}{*}{$P(\mathrm{GLM})$} \\
\hline & \multicolumn{2}{|c|}{1} & \multicolumn{2}{|c|}{2} & \multicolumn{2}{|c|}{3} & \multicolumn{2}{|c|}{4} & \\
\hline & Mean & SD & Mean & SD & Mean & SD & Mean & SD & \\
\hline Intake levels & $0.51^{\mathrm{b}}$ & 0.47 & $4 \cdot 84^{b}$ & 1.96 & $10 \cdot 09^{b}$ & $1 \cdot 12$ & $72 \cdot 46^{\mathrm{a}}$ & $118 \cdot 82$ & $<0.001$ \\
\hline$\alpha$-Tocopherol concentrations & $26 \cdot 13^{\mathrm{b}}$ & 8.26 & $27 \cdot 34^{\mathrm{b}}$ & $6 \cdot 80$ & $27 \cdot 27^{\mathrm{b}}$ & $5 \cdot 26$ & $31.51^{\mathrm{a}}$ & $10 \cdot 23$ & 0.001 \\
\hline$\gamma$-Tocopherol concentrations & 1.58 & 0.74 & 1.68 & 1.08 & 1.36 & 0.76 & $1 \cdot 26$ & 0.78 & 0.077 \\
\hline
\end{tabular}

GLM, general linear model.

${ }^{\mathrm{a}, \mathrm{b}}$ Mean values with unlike superscript letters were significantly different between the quartiles $(P<0.05)$

${ }^{*}$ GLM univariate analysis, adjusted for age and sex, was carried out to determine significance. 
Table 8. Mean daily vitamin $E$ intake $(\mathrm{mg} / \mathrm{d}$ ) from food and supplement sources and plasma $\alpha$ - and $\gamma$-tocopherol concentrations ( $\mu \mathrm{mol} / \mathrm{l}$ ) of consumers categorised by supplement types

\begin{tabular}{|c|c|c|c|c|c|c|c|c|c|c|c|c|c|c|c|}
\hline & \multicolumn{14}{|c|}{ Supplement types } & \multirow[b]{2}{*}{$\begin{array}{c}P \text { (one-way } \\
\text { ANOVA) }\end{array}$} \\
\hline & \multicolumn{2}{|c|}{$\begin{array}{l}\text { Vitamin } \mathrm{E} \\
\qquad(n 5)^{\star}\end{array}$} & \multicolumn{2}{|c|}{$\begin{array}{l}\text { Multivitamin } \\
\text { and fish } \\
\text { oil }(n 22)\end{array}$} & \multicolumn{2}{|c|}{$\begin{array}{l}\text { Seed oil } \\
(n 12)\end{array}$} & \multicolumn{2}{|c|}{$\begin{array}{l}\text { Multivitamin } \\
\quad(n 77)^{\star}\end{array}$} & \multicolumn{2}{|c|}{$\begin{array}{l}\text { Others } \\
(n 10) \dagger\end{array}$} & \multicolumn{2}{|c|}{$\begin{array}{l}\text { Fish and } \\
\text { seed oil } \\
(n 7)\end{array}$} & \multicolumn{2}{|c|}{$\begin{array}{l}\text { Fish oil } \\
(n 75)\end{array}$} & \\
\hline \multicolumn{16}{|c|}{ Vitamin E concentrations (mg/recommended doseł) } \\
\hline Median & \multirow{2}{*}{\multicolumn{2}{|c|}{$\begin{array}{c}268 \\
166-546\end{array}$}} & \multirow{2}{*}{\multicolumn{2}{|c|}{$\begin{array}{c}20 \\
10 \cdot 3-107 \cdot 2\end{array}$}} & \multirow{2}{*}{\multicolumn{2}{|c|}{$\begin{array}{c}10 \\
2 \cdot 7-87\end{array}$}} & \multirow{2}{*}{\multicolumn{2}{|c|}{$\begin{array}{c}10 \\
1.4-100\end{array}$}} & \multirow{2}{*}{\multicolumn{2}{|c|}{$\begin{array}{c}10 \\
0.3-45\end{array}$}} & \multirow{2}{*}{\multicolumn{2}{|c|}{$\begin{array}{c}5 \cdot 4 \\
0.3-30\end{array}$}} & \multirow{2}{*}{\multicolumn{2}{|c|}{$\begin{array}{c}0.74 \\
0.2-20.5\end{array}$}} & \\
\hline \multirow[t]{2}{*}{ Range } & & & & & & & & & & & & & & & \\
\hline & Mean & SD & Mean & SD & Mean & SD & Mean & SD & Mean & SD & Mean & SD & Mean & SD & \\
\hline \multicolumn{16}{|l|}{ Mean daily intake } \\
\hline Food sources & $12 \cdot 2$ & 4.4 & 11.9 & $6 \cdot 3$ & $9 \cdot 3$ & $7 \cdot 3$ & $10 \cdot 9$ & $6 \cdot 2$ & 8.4 & 3.3 & $12 \cdot 1$ & 4.7 & $11 \cdot 1$ & 4.7 & 0.636 \\
\hline $\begin{array}{l}\text { Supplement } \\
\text { sources }\end{array}$ & $279 \cdot 2^{a}$ & $207 \cdot 0$ & $24 \cdot 5^{\mathrm{b}}$ & $24 \cdot 3$ & $52 \cdot 4^{b}$ & $148 \cdot 0$ & $20 \cdot 0^{\mathrm{b}}$ & $35 \cdot 8$ & $12 \cdot 8^{\mathrm{b}}$ & $24 \cdot 1$ & $9 \cdot 3^{\mathrm{b}}$ & $12 \cdot 2$ & $8.9^{b}$ & $46 \cdot 0$ & $<0.001$ \\
\hline \multicolumn{16}{|c|}{ Plasma concentrations } \\
\hline$\alpha$-Tocopherol & $45 \cdot 0^{\mathrm{a}}$ & $13 \cdot 8$ & $27 \cdot 5^{\mathrm{b}}$ & $7 \cdot 7$ & $25 \cdot 0^{\mathrm{b}}$ & 4.4 & $29 \cdot 0^{\mathrm{b}}$ & 7.3 & $27 \cdot 8^{\mathrm{b}}$ & $6 \cdot 4$ & $28 \cdot 7^{\mathrm{b}}$ & 8.7 & $26 \cdot 6^{b}$ & $7 \cdot 8$ & $<0.001$ \\
\hline$\gamma$-Tocopherol & $1 \cdot 2$ & 0.8 & 1.2 & 1.0 & 1.5 & 0.7 & 1.5 & 0.9 & 1.2 & 1.0 & $2 \cdot 1$ & 1.4 & 1.5 & 0.7 & 0.338 \\
\hline
\end{tabular}

${ }^{a, b}$ Mean values with unlike superscript letters were significantly different between the supplement consumers $(P<0.05)$.

* Multi-supplement consumers $(n 5)$ were included in these categories. These categories contributed the most to vitamin $\mathrm{E}$ intake.

† 'Others' included protein powders, protein and energy drinks, weight-loss products, isoflavone supplements, Se supplements and Mg supplements

$\ddagger$ The manufacturer's recommendation was used as the unit of vitamin $E$ supplements.

intake in the US diet are 'ready-to-eat cereals' and 'cakes, cookies, pies and doughnuts' ${ }^{(49)}$. In the US survey, the 'ready-to-eat cereals' group contained products fortified with synthetic vitamin $\mathrm{E}^{(50)}$, which is not the case in Ireland or the UK. In the present study, only $6 \%$ of the ready-to-eat cereals consumed were fortified with vitamin E. It is also worth noting that synthetic forms of vitamin $\mathrm{E}$ are less bioavailable than the natural form ${ }^{(51)}$, and Maras et $a l^{(49)}$ suggested that the actual available dietary vitamin $\mathrm{E}$ amounts from 'ready-to-eat cereals' may be lower than those reported in the US publication for this reason. Similar to a previous study $^{(50)}$, in the present study also, it was found that $0.7 \%$ of the foods (eighteen from a total of 2552 foods) were fortified with vitamin $\mathrm{E}$ and that fortification with vitamin $\mathrm{E}$ had little impact on total vitamin $\mathrm{E}$ intake. Thus, in the present study, foods fortified with vitamin E were not selected as an individual food group due to very low numbers. To our knowledge, the effect of fortified foods on plasma vitamin $\mathrm{E}$ concentrations at a population level has not been investigated.

The effects of age and sex on vitamin E intake were clearly observed in the present study. Older participants had a higher vitamin E intake as they consumed more vitamin E-rich foods, such as dairy spreads, compared with younger participants (data not shown). A greater prevalence of supplement use was also found in those aged $>64$ years, particularly in females $^{(20)}$. The consumption of supplements by females was the main factor contributing to the sex effects. Among supplement consumers, vitamin E intake from supplements in females aged 36-50 years was five times higher than that in male supplement consumers, while female supplement consumers aged > 64 years consumed thirteen times more vitamin $\mathrm{E}$ (expressed on a total energy basis) than their male counterparts. The results showed that the consumption of supplements had a significant influence on vitamin $\mathrm{E}$ intake in females, $32 \%$ of whom had intake levels below the EU RDA based on vitamin E intake from food sources. Similar effects of age and sex were observed in other studies. The US NHANES 1999-2002 reported that vitamin E intake from supplements increased with an increase in age and that females consumed significantly more vitamin E from supplement sources than males ${ }^{(52)}$. An effect of sex was also observed in the French Supplementation en Vitamines et Mineraux AntioXydants (SU.VI.MAX) Study; the vitamin E intake levels of females were significantly higher than those of males ${ }^{(53)}$.

An effect of age on plasma $\alpha$-tocopherol concentrations was observed across the total population and in both supplement consumers and non-consumers, with plasma $\alpha$-tocopherol concentrations increasing with age. This was in agreement with findings from a Swiss survey of non-consumers of supplements, where both plasma $\alpha$ - and $\gamma$-tocopherol concentrations were found to increase with age ${ }^{(54)}$. The effect of sex on plasma $\alpha$-tocopherol concentrations in the total population was attributable to the higher plasma $\alpha$-tocopherol concentrations of female supplement consumers compared with their male counterparts, influenced by the amount of supplements consumed. Other studies have also suggested that the main indicator of plasma $\alpha$ - and $\gamma$-tocopherol concentrations is vitamin E supplement intake ${ }^{(9,55,56)}$, where the plasma $\alpha$-tocopherol concentrations of vitamin E supplement consumers were found to be substantially higher than those of non-consumers.

With regard to the effect of supplement sources on plasma $\alpha$-tocopherol concentrations, only high vitamin $\mathrm{E}$ intake, as demonstrated by those in the fourth quartile of intake in the present study, had a significant effect. It is perhaps unsurprising that food sources are unlikely to provide such high vitamin $\mathrm{E}$ amounts and that supplement sources therefore have a larger impact on plasma $\alpha$ - and $\gamma$-tocopherol concentrations than food sources. A similar study in a Costa Rican population examined plasma $\alpha$-tocopherol concentrations across the reported $\alpha$-tocopherol intake quintiles ${ }^{(57)}$ and also found a 
significant increase in plasma $\alpha$-tocopherol concentrations across quintiles of intake, reporting that the significance was mainly attributable to those in the highest intake quintile. Similar to the present results, several studies have indicated that with increasing total vitamin $\mathrm{E}$ intake, plasma $\alpha$-tocopherol concentrations increase and $\gamma$-tocopherol concentrations decrease $^{(9,58)}$, which is hypothesised to be due to competition for the $\alpha$-tocopherol hepatic transfer protein. Studies have shown that the hepatic $\alpha$-tocopherol transfer protein preferentially incorporates $\alpha$-tocopherol into VLDL, potentially explaining the rise in $\alpha$-tocopherol concentrations with increasing intakes and concomitant decrease in $\gamma$-tocopherol concentrations ${ }^{(59)}$. Examination of the impact of factors such as smoking habits ${ }^{(16)}$ and $\mathrm{BMI}^{(60)}$, which are known to have an effect on plasma $\alpha$ - and $\gamma$-tocopherol concentrations, was beyond the scope of the present study.

The present study is one of the first to examine the impact of supplement types on vitamin $\mathrm{E}$ intake and plasma $\alpha$ - and $\gamma$-tocopherol concentrations in a national population. The results indicated that the types of supplements consumed had a significant impact on the reported vitamin $\mathrm{E}$ intake, reflecting the wide range of recommended doses in different types of supplements. As there was no significant difference in vitamin $\mathrm{E}$ intake from food sources among consumers of different types of supplements, the differences in intake were mainly attributable to the consumption of supplements. Among the consumers of different types of supplements, only 'vitamin E' supplement consumers had a significantly higher dietary vitamin $\mathrm{E}$ intake compared with other groups. In agreement with vitamin $\mathrm{E}$ intake quartile results, 'vitamin $\mathrm{E}$ ' supplement consumers had significantly higher plasma $\alpha$-tocopherol concentrations and slightly lower plasma $\boldsymbol{\gamma}$-tocopherol concentrations when compared with consumers of other supplements.

In conclusion, vitamin $\mathrm{E}$ intake levels have been characterised for the first time in an Irish adult population. In general, the mean daily vitamin $\mathrm{E}$ intake of Irish adults was in accordance with the levels recommended by the EU and IOM, but females appeared to be reliant on supplementation to achieve these recommended levels. In Irish adults, vitamin $\mathrm{E}$ intake from supplements varied across consumers of different types of supplements, while plasma $\alpha$ - and $\boldsymbol{\gamma}$-tocopherol concentrations were found to increase and decrease, respectively, with an increase in vitamin E intake. 'Vitamin E' supplements seemed to be the factors contributing to high vitamin $\mathrm{E}$ intake levels and plasma $\alpha$-tocopherol concentrations.

\section{Supplementary material}

To view supplementary material for this article, please visit http://dx.doi.org/10.1017/S0007114514002438

\section{Acknowledgements}

The authors thank the respondents and fieldworkers of the NANS for their contribution to the data collection process.

The present study received financial support from the Irish Department of Agriculture, Food and the Marine under the
Food for Health Research Initiative. Y. Z. is in receipt of a PhD studentship from the China Scholarship Council 2011-2015.

The authors' contributions are as follows: Y. Z. conducted the sample analysis and prepared the manuscript under the supervision of F. J. M. and E. R. G., supported by B. A. M. and M. J. G. All authors read and approved the final version of the manuscript.

None of the authors has any conflicts of interest to declare.

\section{References}

1. Burton GW (1994) Vitamin E: molecular and biological function. Proc Nutr Soc 53, 251-262.

2. Traber MG \& Atkinson J (2007) Vitamin E, antioxidant and nothing more. Free Radic Biol Med 43, 4-15.

3. Davies JE (2007) The pharmacological basis of therapeutics. pp. 20-21 [LL Brunton, JS Lazo and KL Parker, editors]. London: BMJ Publishing Group Limited.

4. Saremi A \& Arora R (2010) Vitamin E and cardiovascular disease. Am J Ther 17, E56-E65.

5. Sun Y, Ma A, Li Y, et al. (2012) Vitamin E supplementation protects erythrocyte membranes from oxidative stress in healthy Chinese middle-aged and elderly people. Nutr Res 32, 328-334.

6. Agler AH, Kurth T, Gaziano JM, et al. (2011) Randomized vitamin $\mathrm{E}$ supplementation and risk of chronic lung disease in the Women's Health Study. Thorax 66, 320-325.

7. Kasparek S (1980) Chemistry of tocopherols and tocotrienols. In Vitamin E: A Comprehensive Treatise, pp. 7-65 [LJ Machlin, editor]. New York: Marcel Dekker.

8. Brigelius-Flohe R \& Traber MG (1999) Vitamin E: function and metabolism. FASEB J 13, 1145-1155.

9. White E, Kristal AR, Shikany JM, et al. (2001) Correlates of serum alpha- and gamma-tocopherol in the women's health initiative. Ann Epidemiol 11, 136-144.

10. McLaughlin PJ \& Weihrauch JL (1979) Vitamin E content of foods. J Am Diet Assoc 75, 647-665.

11. Yu W, Jia L, Park SK, et al. (2009) Anticancer actions of natural and synthetic vitamin $\mathrm{E}$ forms: $R R R-\alpha$-tocopherol blocks the anticancer actions of $\gamma$-tocopherol. Mol Nutr Food Res 53, 1573-1581.

12. Tetens I, Biltoft-Jensen A, Spagner C, et al. (2011) Intake of micronutrients among Danish adult users and non-users of dietary supplements. Food Nutr Res 55, 7153-7161.

13. Whiting SJ, Langlois KA, Vatanparast H, et al. (2011) The vitamin D status of Canadians relative to the 2011 Dietary Reference Intakes: an examination in children and adults with and without supplement use. Am J Clin Nutr 94, $128-135$.

14. Gao X, Martin A, Lin H, et al. (2006) Alpha-tocopherol intake and plasma concentration of Hispanic and non-Hispanic white elders is associated with dietary intake pattern. $J$ Nutr 136, 2574-2579.

15. Clarke MW, Ward NC, Wu JH, et al. (2006) Supplementation with mixed tocopherols increases serum and blood cell gamma-tocopherol but does not alter biomarkers of platelet activation in subjects with type 2 diabetes. Am J Clin Nutr 83, 95-102.

16. Faure H, Preziosi P, Roussel AM, et al. (2006) Factors influencing blood concentration of retinol, alpha-tocopherol, vitamin $\mathrm{C}$, and beta-carotene in the French participants of the SU.VI.MAX trial. Eur J Clin Nutr 60, 706-717.

17. Huang HY \& Appel LJ (2003) Supplementation of diets with alpha-tocopherol reduces serum concentrations of gammaand delta-tocopherol in humans. J Nutr 133, 3137-3140. 
18. Harrington J, Perry I, Lutomski J, et al. (2008) SLAN 2007: Survey of Lifestyle, Attitudes and Nutrition in Ireland. Dietary Habits of the Irish Population. Department of Health and Children. Dublin: The Stationery Office.

19. O'Brien MM, Kiely M, Harrington KE, et al. (2001) The North/South Ireland Food Consumption Survey: vitamin intakes in 18-64 year-old adults. Public Health Nutr 4, 1069-1079.

20. Irish Universities Nutrition Alliance (2011) National Adult Nutrition Survey Summary Report. http://www.iuna.net. Dublin: Food Safety Promotion Board.

21. Gilsenan MB, Lambe J \& Gibney MJ (2002) Irish National Food Ingredient Database: application for assessing patterns of additive usage in foods. Food Addit Contam 19, 1105-1115.

22. Harrington KE, Robson PJ, Kiely M, et al. (2001) The North/ South Ireland food consumption survey: survey design and methodology. Public Health Nutr 4, 1037-1042.

23. Food Standards Agency (2002) McCance and Widdowson's The Composition of Foods, 6th summary ed. Cambridge: Royal Society of Chemistry.

24. Holland B, Welch A, Unwin I, et al. (1995) McCance E Widdowson's The Composition of Foods, 5th ed. London: HMSO.

25. Holland B, Unwin ID \& Buss DH (1992) Fruits and Nuts. First Supplement to McCance \& Widdowson's The Composition of Foods, 5th ed. London: HMSO.

26. Chan W, Brown J \& Buss DH (1994) Miscellaneous Foods. Fourth Supplement to McCance \& Widdowson's The Composition of Foods, 5th ed. London: HMSO.

27. Chan W, Brown J \& Church S (1996) Meat Products and Dishes. Sixth Supplement to McCance \& Widdowson's The Composition of Foods, 5th ed. London: HMSO

28. Chan W, Brown J \& Lee S (1995) Meat, Poultry and Game Fifth Supplement to McCance \& Widdowson's The Composition of Foods, 5th ed. London: HMSO.

29. Holland B, Brown J \& Buss DH (1993) Fish and Fish Products. Third Supplement to McCance \& Widdowson's The Composition of Foods, 5th ed. London: HMSO.

30. Holland B, Unwin I \& Buss D (1991) Vegetables, Herbs and Spices. Fifth Supplement to McCance \& Widdowson's The Composition of Foods, 4th ed. London: HMSO

31. Holland B, Unwin I \& Buss D (1989) Milk Products and Eggs. Fourth Supplement to McCance \& Widdowson's The Composition of Foods, 4th ed. London: HMSO.

32. Holland B, Unwin I \& Buss D (1988) Cereal and Cereal Products. Third Supplement to McCance \& Widdowson's The Composition of Foods, 4th ed. London: HMSO.

33. Holland B, Welch A \& Buss D (1996) Vegetable Dishes. Second Supplement to McCance \& Widdowson's The Composition of Foods, 5th ed. London: HMSO.

34. Black LJ, Ireland J, Møller A, et al. (2011) Development of an on-line Irish food composition database for nutrients. J Food Comp Anal 24, 1017-1023.

35. United States Department of Agriculture (2011) National Nutrient Database for Standard Reference, Release 24. Beltsville, MD: Agricultural Research Service, Beltsville Human Nutrition Research Center.

36. Cashman KD, Muldowney S, McNulty B, et al. (2013) Vitamin D status of Irish adults: findings from the National Adult Nutrition Survey. Br J Nutr 109, 1248-1256.

37. Siluk D, Oliveira RV, Esther-Rodriguez-Rosas M, et al. (2007) A validated liquid chromatography method for the simultaneous determination of vitamins $\mathrm{A}$ and $\mathrm{E}$ in human plasma. J Pharm Biomed Anal 44, 1001-1007.
38. Gueguen S, Herbeth B, Siest G, et al. (2002) An isocratic liquid chromatographic method with diode-array detection for the simultaneous determination of alpha-tocopherol, retinol, and five carotenoids in human serum. J Chromatogr Sci 40, 69-76.

39. European Commission (2008) Commission directive 2008/ 100/EC of 28 October 2008 amending Council Directive 90/496/EEC on nutrition labelling for foodstuffs as regards recommended daily allowances, energy conversion factors and definitions. Off J Eur Union 285, 9-12.

40. Institue of Medicine (2006) Dietary Reference Intakes Essential Guide Nutrient Requirements. Washington, DC: National Academies Press.

41. Wearne SJ \& Day M (1999) Clues for the development of food-based dietary guidelines: how are dietary targets being achieved by UK consumers? Br J Nutr 81, S119-S126.

42. Goldberg GR, Black AE, Jebb SA, et al. (1991) Critical evaluation of energy intake data using fundamental principles of energy physiology: 1. Derivation of cut-off limits to identify under-recording. Eur J Clin Nutr 45 , 569-581.

43. European Food Safety Authority (2003) The Tolerable Upper Intake Levels of Vitamin E. Brussels: Scientific Committee on Food.

44. Wang Z, Joshi AM, Ohnaka K, et al. (2012) Dietary intakes of retinol, carotenes, vitamin $\mathrm{C}$, and vitamin $\mathrm{E}$ and colorectal cancer risk: the Fukuoka colorectal cancer study. Nutr Cancer 64, 798-805.

45. Gao X, Wilde PE, Lichtenstein AH, et al. (2006) The maximal amount of dietary alpha-tocopherol intake in U.S. adults (NHANES 2001-2002). J Nutr 136, 1021-1026.

46. Szponar L, Sekula W, Nelson M, et al. (2001) The household food consumption and anthropometric survey in Poland. Public Health Nutr 4, 1183-1186.

47. Ruston D, Hoare J, Henderson L, et al. (2004) The National Diet E Nutrition Survey: Adults Aged 19 to 64 Years - Vitamin and Mineral Intake and Urinary Analytes. London: The Stationery Office.

48. Fulgoni VL 3rd, Keast DR, Bailey RL, et al. (2011) Foods, fortificants, and supplements: where do Americans get their nutrients? J Nutr 141, 1847-1854.

49. Maras JE, Bermudez OI, Qiao N, et al. (2004) Intake of alpha-tocopherol is limited among US adults. J Am Diet Assoc 104, 567-575.

50. Hannon EM, Kiely M \& Flynn A (2007) The impact of voluntary fortification of foods on micronutrient intakes in Irish adults. Br J Nutr 97, 1177-1186.

51. Traber MG, Rader D, Acuff RV, et al. (1998) Vitamin E doseresponse studies in humans with use of deuterated $R R R-$ alpha-tocopherol. Am J Clin Nutr 68, 847-853.

52. Chun OK, Floegel A, Chung SJ, et al. (2010) Estimation of antioxidant intakes from diet and supplements in US adults. J Nutr 140, 317-324.

53. Galan P, Viteri FE, Bertrais S, et al. (2005) Serum concentrations of beta-carotene, vitamins $\mathrm{C}$ and $\mathrm{E}$, zinc and selenium are influenced by sex, age, diet, smoking status, alcohol consumption and corpulence in a general French adult population. Eur J Clin Nutr 59, 1181-1190.

54. Winklhofer-Roob MB, van't Hof MA \& Shmerling DH (1997) Reference values for plasma concentrations of vitamin $\mathrm{E}$ and $\mathrm{A}$ and carotenoids in a Swiss population from infancy to adulthood, adjusted for seasonal influences. Clin Chem $\mathbf{4 3}$, 146-153.

55. Krasinski SD, Russell RM, Otradovec CL, et al. (1989) Relationship of vitamin A and vitamin $\mathrm{E}$ intake to fasting plasma retinol, retinol-binding protein, retinyl esters, 
carotene, alpha-tocopherol, and cholesterol among elderly people and young adults: increased plasma retinyl esters among vitamin A-supplement users. Am J Clin Nutr 49, $112-120$.

56. Talegawkar SA, Johnson EJ, Carithers T, et al. (2007) Total $\alpha$-tocopherol intakes are associated with serum $\alpha$-tocopherol concentrations in African American adults. J Nutr 137, 2297-2303.

57. El-Sohemy A, Baylin A, Ascherio A, et al. (2001) Populationbased study of alpha- and gamma-tocopherol in plasma and adipose tissue as biomarkers of intake in Costa Rican adults. Am J Clin Nutr 74, 356-363.
58. Ascherio A, Stampfer MJ, Colditz GA, et al. (1992) Correlations of vitamin $\mathrm{A}$ and $\mathrm{E}$ intakes with the plasma concentrations of carotenoids and tocopherols among American men and women. J Nutr 122, 1792-1801.

59. Traber M, Sokol R, Kohlschütter A, et al. (1993) Impaired discrimination between stereoisomers of alpha-tocopherol in patients with familial isolated vitamin E deficiency. J Lipid Res 34, 201-210.

60. Vogel S, Contois JH, Tucker KL, et al. (1997) Plasma retinol and plasma and lipoprotein tocopherol and carotenoid concentrations in healthy elderly participants of the Framingham Heart Study. Am J Clin Nutr 66, 950-958. 